\title{
Defined Observation
}

National Cancer Institute

\section{Source}

National Cancer Institute. Defined Observation. NCI Thesaurus. Code C93371.

An activity whose intention is to obtain a result by observing, monitoring, measuring or otherwise qualitatively or quantitatively gathering data or information about one or more aspects of the physiologic or psychologic state of an entity. 